REVISTA ANDALUZA DE ANTROPOLOGÍA.

NÚMERO 12: PATRIMONIO INMATERIAL: REDUCCIONISMOS, CONFLICTOS E

INSTRUMENTALIZACIONES.

INTANGIBLE CULTURAL HERITAGE: REDUCTIONISMS, CONFLICTS AND

INSTUMENTALIZATIONS.

MARZO DE 2017

ISSN 2174-6796

[pp. 180-183]

http://dx.doi.org/10.12795/RAA.2017.12.09

\title{
STEPPUTAT, FINN (ed.) (2016) Governing the dead. Sovereignity and the politics of dead bodies. Manchester: Manchester University Press, 256 pp.
}

\section{Beltrán Roca Martínez \\ Universidad de Cádiz}

Aunque Governing the dead (Gobernar a los muertos) es un libro colectivo, forma parte de un proyecto personal del editor, Finn Stepputat -investigador del Instituto Danés de Estudios Internacionales- en el que ha estado trabajando muchos años, influido por su propia trayectoria biográfica. Los interrogantes que motivan esta monografía son: ¿Por qué las sociedades Occidentales viven de espaldas a la muerte? ¿Qué racionalidad orienta el papel del Estado en la transición de la vida hacia la muerte? Investiga, por tanto, la biopolítica que opera en la gobernanza y la gestión de los cuerpos muertos.

Con esta publicación Stepputat da un paso más en su investigaciones etnográficas sobre el Estado y la soberanía (Hansen y Stepputat, 2005), extendiendo las reflexiones al gobierno de los muertos. La transición hacia la muerte y el manejo de los cuerpos de los fallecidos están estrictamente regulados por el aparato del Estado. Aunque en ocasiones esa regulación es objeto de negociación con otras entidades privadas, sociales y religiosas, en última instancia es el Estado la entidad que posee la máxima autoridad. Así, la "burocracia de la muerte" forma parte del ejercicio de la soberanía por parte del Estado. La soberanía pasa a ser entendida de este modo en un sentido amplio, como 
el "efecto de prácticas que están fundamentalmente relacionadas con el cuerpo y con los asuntos de la vida y la muerte" (p. 4). Esta aproximación permite estudiar cómo la gestión de los muertos está conectada con la formación, territorialización y pertenencia a comunidades políticas y morales. Se adentra, por tanto, en una fértil área de estudio a la que la antropología o la sociología política, salvo contadas excepciones, no ha prestado el suficiente interés.

El segundo capítulo, escrito por el editor, es una revisión delos enfoques teóricos utilizados por los autores de los diferentes capítulos del libro sobre la intersección entre los cuerpos muertos y la práctica de la soberanía. Estudia las teorías psicoanalíticas, la teoría crítica, el estructural-funcionalismo antropológico, así como las recientes aproximaciones teóricas sobre la agencia y la materialidad.

Stepputat divide los capítulos descriptivos (del tercero al décimo) en dos secciones. La primera sección, "Contención y negociación”, analiza cómo los Estados tratan de contener y separar los cuerpos fallecidos, y cómo ese esfuerzo es negociado con otras entidades (religiosas, sociales...). La segunda sección, titulada “Transgresión”, explora cómo diferentes entidades ejercen la soberanía desafiando las leyes sobre el uso legítimo de la violencia y transgrediendo las normas sobre el tratamiento con dignidad de los cuerpos fallecidos.

El capítulo tercero, "El funeral adecuado: Muerte, paisaje y poder entre los tuvanos Duha del norte de Mongolia", la autora, Benedikte Møller Kristensen, analiza los "entierros al aire libre" en los Duha de Mongolia como casos extremos opuestos a la contención, así como el conflicto entre este pueblo y sus chamanes, por un lado, y el Estado soviético, por otro, que trataba de reclamar los cuerpos de los fallecidos. El ritual del "entierro al aire libre" tuvo así un efecto de nacionalización del paisaje en el contexto post-soviético. El capítulo cuarto, "Zona muerta: Contaminación y el muerto negado en el Saigón post bélico", escrito por Christoph Robert, reflexiona sobre el concepto de "zonas muertas". Éstas son espacios en los que el cementerio pierde su carácter de contenedor que separa a los muertos de los vivos. Son zonas contaminadas, pobres y marginales, con cementerios periféricos parcialmente abandonados. El antropólogo investiga los conflictos entre el Estado y la población, movilizada contra los intentos de erradicar estos espacios en base a la "deuda con los muertos".

El capítulo siguiente, titulado "Cuerpos viajando: negociando demandas de soberanía en la repatriación post mortem de un oaxaqueño, escrito por Lars Ove Trans, describe el proceso de repatriación hacia México de un migrante fallecido en Estados Unidos. El acontecimiento se ubica en el contexto de la ley mexicana por la cual el Estado apoya la repatriación de cuerpos para ser enterrados en suelo nacional como expresión de la "última prueba de pertenencia". Sin embargo, los migrantes pertenecen a múltiples 
comunidades (nacionales, locales y transnacionales) que toman parte en la negociación sobre el destino de los cuerpos.

Los capítulos seis y siete, escritos por Henri Myrttinen y Joost Fontein respectivamente, tratan el problema delas exhumaciones en la formación de Estados-nación independientes. A partir de los casos de Timor Oriental y el norte de Zimbabwe, se demuestra que el proceso de selección de los restos humanos sobre los que se basa la construcción de una nación, son objeto de conflicto y negociación. Exhumaciones sin autorización, por ejemplo, son utilizadas como formas de acción colectiva por ex combatientes en su intento por desafiar jerarquías de los cuerpos muertos en el proceso de independencia dentro de la narrativa oficial del Estado. En el caso de Zimbabwe, las exhumaciones sirven para la contestación política del partido opositor, evidenciando la crueldad del régimen colonial, mientras que el partido en el poder trata de obtener rédito de la ambigüedad de los significados sociales de estos restos.

La segunda parte del libro, titulada “Transgresión", incluye una serie de casos en los que los aspectos necropolíticos de la soberanía se imponen sobre la biopolítica a través de prácticas sobre los cuerpos muertos que generalmente transgreden las leyes del Estado. En el capítulo octavo, "Gobernando a los desaparecidos-vivos y los desaparecidosmuertos", se estudia la violenta búsqueda de la soberanía en la dictadura argentina. El autor, Antonius Robben, argumenta que mediante el estado de emergencia las autoridades pueden trasgredir las leyes que regulan la vida y la muerte. La dictadura militar argentina de finales de 1970 trató de imponer la soberanía cultural a través de prácticas necropolíticas y biopolíticas, como las abducciones o la tortura, que generaban cuerpos que no estaban ni vivos ni muertos. El capítulo siguiente, escrito por Regnar Kristensen, también ejemplifica cómo el Estado mexicano, en la lucha contra la droga, transgrede sus propias reglas sobre los cuerpos muertos. Los excesos, humillaciones y ridiculizaciones de los cuerpos de los enemigos fallecidos, que contrasta con el tratamiento burocrático de protección del cuerpo durante su desplazamiento, están relacionados, según el autor, con ciertas ideas católicas sobre los espíritus de los muertos.

Richard Kernaghan, en el capítulo décimo, titulado "El tiempo como el clima”, estudia la práctica por parte de las guerrillas de Sendero Luminoso en Perú de colocar cuerpos en descomposición en las carreteras con el objeto de crear nuevas subjetividades políticas y nuevas leyes. Kernaghan analiza cómo las imágenes revelan ideas sobre las relaciones de propiedad y las relaciones sociales locales. El capítulo siguiente, "Gobernando a través del cuerpo femenino mutilado: cuerpos, política corporal y contestación en Guatemala contemporánea", de Ninna N. Sørensen, utiliza la perspectiva de género para investigar el feminicidio en Guatemala. A partir del estudio de la evolución de los asesinatos de mujeres y de los sitios y el estado en que se encontraban los cuerpos, la autora sugiere 
que el feminicidio está relacionado con la creciente influencia de poderes empresariales y su formación de comunidades políticas, todo ello amparado por un Estado patriarcal.

El epílogo, escrito por John Borneman, vuelve a la cuestión inicial de por qué los vivos tratan de gobernar - con escaso éxito - sobre los muertos utilizando como ejemplo el caso de los líderes comunistas tras el colapso de la Unión Soviética. Detrás del intento de gobernar a los muertos se esconden fines de legitimación política, y se emplean diferentes modos de tratar con el pasado: represión, duelo y melancolía.

En definitiva, los capítulos que contiene Governing the dead nos ofrecen importantes claves con las que comprender la forma en que funciona la soberanía. Stepputat da un paso adelante en la línea de investigación en la que lleva años trabajando, mostrándonos a través de una multiplicidad de casos de diferentes contextos históricos y geográficos, cómo los Estados tratan de gestionar a los cuerpos muertos, y los conflictos que ello genera con otras entidades. Y cómo ello nos obliga a repensar el mismo concepto de soberanía.

\section{REFERENCIAS BIBLIOGRÁFICAS}

Hansen, T. B. y Stepputat, F. (2005) Sovereign bodies. Citizens, migrants and States in the postcolonial world. Princeton, NJ: Princeton University Press. 